\title{
Restorative Justice and Domestic Violence
}

\author{
DEREK R. BROOKES
}

September 2019

\begin{abstract}
[D]omestic violence is probably the most problematic area of application [of restorative justice], and here great caution is advised. - Howard Zehr, 2003
\end{abstract}

\begin{abstract}
Introduction
This paper explores the feasibility of offering a restorative justice (RJ) approach in cases of domestic violence (DV). I argue that widely used RJ processes-such as 'conferencing' - are unlikely to be sufficiently safe or effective in cases of DV, at least as these processes are standardly designed and practiced (Sections 1-6). ${ }^{2}$ I then support the view that if $\mathrm{RJ}$ is to be used in cases of DV, then new specialist processes will need to be co-designed with key stakeholders to ensure they embody not only RJ principles, but also feminist theory ${ }^{3}$ and the concept of transformative justice (Section 7).
\end{abstract}

\section{ADDRESSING CUMULATIVE HARM}

\subsection{Single-incident Focus}

Standard RJ processes have been primarily designed to focus on repairing the harm caused by a single offence or crime. ${ }^{4}$ There is an institutional reason for this focus: RJ programs are usually set up to take referrals from the criminal justice system; and so they automatically take on many of the assumptions embedded in criminal law, one of which is to identify and treat criminal behaviour in terms of individual acts taken in isolation.

The problem is that DV cannot be reduced to one isolated incident, or even one type of offence. DV involves a series of multiple types of harmful acts that are inflicted against the same person over time. Moreover, this behaviour tends to increase in severity, both in terms of the degree of violence used and as a result of the cumulative impact. In other words, the harm caused by DV cannot be confined to a single offence, no matter how serious. But then it follows that, much like criminal justice prosecutions, standard RJ processes are inherently ill-equipped to address the kind of harm that is generally caused by DV. ${ }^{5}$ 
It might be thought that, unlike legislatively bound court procedures, RJ processes are more flexible, and so could be adapted to accommodate the recurring and cumulative impact of DV. But this is precisely the point: standard RJ processes must be substantially re-designed if they are to be used appropriately in the context of DV.

\subsection{The Apology Cycle}

Hearing an apology is one of the key benefits of RJ for those who have been harmed. However, men who are responsible for inflicting DV routinely use apologies as a recurring tool of abuse (often called the 'apology cycle'). This strategy works by exploiting their partner's hope that the abuse will stop. Over time, the effectiveness of this strategy will, of course, diminish as she no longer trusts his faux remorse. Nevertheless, the apology cycle is often a key factor in perpetuating the accumulating harm. ${ }^{6}$ Women who are harmed by DV are therefore likely to feel intensely suspicious and distrustful of any RJ process, given that an apology from the person responsible for causing harm is considered to be central. ${ }^{7}$

It might be argued that an apology offered within a RJ process will be more thoroughly prepared and so is more likely to be genuine. But given the prevalence of the apology cycle in cases of DV, it is unlikely that the person harmed will be persuaded that 'he means it this time'. ${ }^{8}$ And facilitators are not in a position to question her judgment: no matter how genuine his depth of remorse might seem to a facilitator, they will not have witnessed the preceding succession of faux apologies. For all the facilitator knows, the apparent levels of remorse expressed on multiple occasions in the past may have been equally, if not more 'impressive' than the remorse displayed in the RJ process. Facilitators have no way of assessing the comparative sincerity of his remorse; and so cannot form a reliable judgement about his current sincerity.

It might be pointed out that this predicament will be true of most non-DV cases: RJ facilitators will rarely have any experience of the person responsible for causing harm prior to the current case, and so will be unable to make a comparative assessment of their sincerity. But this would not usually prevent a RJ process from proceeding safely and effectively. So why should it do so in cases of DV?

However, the specifics of DV make this lack of evidence a serious obstacle. To give a hypothetical: Suppose it was known that a person responsible for causing harm had previously attended multiple RJ meetings. In each case, the person harmed truly believed that he had shown genuine remorse and so she accepted his apology. But then, only a day or two after the meeting, he inflicted the same kind of offence against her. And this pattern continued, time after time. No responsible facilitator would be willing to allow him to participate in yet another RJ process. Given his history of faux apologies, no amount of preparatory work would enable a facilitator to form a reasonable judgement that he 'really means it this time'. But this is precisely the situation in the case of DV, where the apology cycle has been a primary tool of abuse. As one refuge worker put it: 
"He can say he's sorry and acknowledge what he's done until he's blue in the face but what victims want is behaviour change. This needs to be gauged over a period of time. A restorative forum may result in women developing unrealistic expectations of behaviour change and making a decision to stay with him as a result - you only need to see these guys in front of a judge to see how skilled they are at acting to their audience - then everyone may pack up and go home feeling they've done a great day's work and it's all settled. Who monitors behaviour change long term? Do we send them away and wait until next time?" 9

\section{ONGOING RELATIONSHIPS}

Standard RJ processes have been designed primarily for crimes in which the person responsible is not (or at least need not be) in an ongoing relationship with the person harmed, let alone an intimate relationship. There are several features that have consequently been 'built-in' to standard RJ processes, any one of which will make the use of such processes suboptimal and even unsafe for cases in involving DV.

\subsection{Preparation}

RJ processes have been designed to provide participants with a 'safe place' to talk about highly emotional and vulnerable matters: the preparation, structure, layout and setting of a RJ process have all been planned in advance to minimise unnecessary conflict and to maximise the chances of a restorative outcome. So, for instance, the standard RJ process will begin with a preparation phase: the facilitators will meet with the person responsible and the person harmed separately to prepare them for an eventual meeting. At this stage, the facilitators will try to ensure that there is very little, if any, communication between them. If anything does need to be communicated, this would always be done indirectly via the facilitators. Again, there are usually protocols stipulating that, when the participants meet, they should, if possible, use separate entrances and exits. If that is not practical, they should arrive and enter the room separately. These communicative restrictions are in place for good reason: they safeguard the process from unhelpfully pre-emptive conversations or behaviour. But if the participants are in regular unfacilitated contact before a RJ process-as will often be the case with DV-then these standard safe-guards cannot be applied. As a consequence, there could be significant repercussions, in terms of the safety and effectiveness of any RJ process.

Once again, it might be argued that RJ processes could be adapted to take into account this unique context. But this is just to make the point being advanced in this paper: the way in which RJ processes are standardly designed and practiced will need to be significantly amended if they are to be used in a DV context. 


\subsection{Support Persons}

A 'restorative justice conference' is designed to provide both the person harmed and the person responsible with the opportunity to bring their respective support persons to the conference (e.g. family members, friends and/or other types of support persons). But this design feature was incorporated on the assumption that each respective group of support persons would be unlikely to know each other or be in close or regular contact. This is also the optimal situation, for similar reasons to those given above. Unfacilitated and unprepared conversations could easily undermine the process and may even endanger the participants. Hence, standard RJ processes will, where possible, restrict any direct communication between the respective support persons prior to the conference as a way of safeguarding the process.

The problem for DV cases is that the respective support persons are very likely to be in-laws, or mutual friends, or know each other in some other way. So it is far more likely that they will be in regular, unfacilitated contact outside the context of the RJ process. Once again, in such cases, any standard RJ process will need to be amended to take this into account if it is to function optimally and safely in cases of DV.

\subsection{Follow-up}

Standard RJ processes will generally involve only one meeting in which the participants can talk together to address the harm. After this, they will usually have separate followup meetings with the facilitators. It is rare for participants to attend follow-up meetings together, since the process is structured so that they are given ample opportunity to say what needs to be said and to hear what needs to be heard in the meeting itself. Any failure or shortfall in this respect would be due to the unwillingness or inability of the participants. For this reason, unless there are exceptional circumstances, the facilitators would be unlikely to hold an additional meeting.

This does not entail that there is no communication after a meeting. For instance, it is standard practice to let the person harmed know when the person responsible has completed any agreed action plan. But this communication is always done via the facilitators to safeguard the process and the participants. The problem is that, in most cases of DV, the participants will be in an ongoing relationship, or will at least need to communicate about parenting or other joint responsibilities. Hence, this standard safeguard cannot be applied in such cases. So, once again, the way that RJ processes are standardly designed will need to be altered to accommodate this factor. 


\section{INTIMATE RELATIONSHIPS}

\subsection{Triggers}

RJ facilitators will generally not have any professional expertise or background knowledge in the complex and challenging area of DV. For instance, the training provided to RJ facilitators is typically no more than a 2-5 day event, and so will invariably focus on the bare essentials: namely, ensuring that trainees have an adequate grasp of RJ principles, basic psychological assumptions, the structure of one or more standard RJ processes and a range of facilitation skills (e.g. active listening). Again, many RJ programs, as a matter of principle, utilise ordinary members of the community as facilitators. In other programs, facilitators are drawn from backgrounds such as social work or criminal justice. In either case, the facilitators may have some specialist knowledge of DV, but this would be rare and so cannot generally be assumed.

Even if a facilitator does have (or acquires ${ }^{10}$ ) some expertise in DV, the standard time-frames for eligibility assessments and preparation are, in most RJ programs, highly constrained-especially if the program takes referrals as a diversion from prosecution or a deferred sentence. Facilitators will often only have time for one or two meetings within which they are required to make a full assessment and prepare participants for the RJ meeting. With such a limited time-frame, facilitators are crucially dependent upon how each participant is feeling, where they are at in their lives, or how they happen to present themselves at the time. This will include their current state of vulnerability, their willingness to trust the facilitators, their self-awareness, memory recall, general mental health, and so on.

The problem with this lack of training, expertise and/or time is this: in any conference setting, men who inflict DV are proficient at deploying a range of 'microbehaviours' designed to manipulate or coerce their partners without being detected by a third-party. These behaviours can be as subtle as a change in tone of his voice, a certain way of looking at her, or a specific word or phrase. Any one of these behaviours could signal a threat or trigger her memory of abusive behaviour, and thereby compel her, out of fear, into accepting his 'apology' or agreeing to an outcome plan that continues to place her in danger. ${ }^{11}$ Given their standard constraints on time, training and expertise, most facilitators cannot be expected to have the capacity to identify, and therefore challenge the full range of these 'person-specific' strategies. The person harmed may be able to warn facilitators about some of these micro-behaviours in advance. But the detail or extent of her warning will be dependent on a number of contingent and unpredictable factors: for instance, she may not recall all of the behaviours, or be able to describe them with sufficient precision. ${ }^{12}$ She may not even be conscious of many of these triggers, perhaps because she has come to see her partner's behaviour as 'normal' or 'deserved'. ${ }^{13}$ Even if a facilitator manages to identify and 'call-out' a manipulative micro-behaviour in the process of a conference, the automatic nature of psychological triggers is such that it is likely to have already done its coercive work. In any case, a standard RJ process is no more than a brief snap-shot 
in the lives of the participants: even if it were possible to protect the person harmed from these strategies for the duration of a RJ meeting, this is unlikely to shift the balance of power over the longer-term.

In short, standard RJ processes have not been designed-and facilitators are not typically equipped - to be able to offer adequate protection from this kind of hidden manipulation or coercion. Even if the facilitators could do so, this brief moment of 'empowerment' could mislead the person harmed into agreeing to an outcome plan that will be unsafe for her. ${ }^{14}$ On both counts, then, the way that RJ processes are standardly designed and practiced could potentially place the person harmed at significant risk of continued abuse and re-traumatisation.

\subsection{Voice}

A core part of every standard RJ process involves the person harmed expressing in some detail how they have been affected by the wrongdoing. Part of the reason for this is to make sure the person responsible is fully aware of the consequences of their actions. This can have a powerful impact on their conscience, and thus motivate them to desist from such actions in the future. It also enables the person harmed to be 'heard' and thus for them to feel re-empowered, often for the first time since the offence.

However, in the context of DV, it is not clear that this part of a RJ process will work in the usual way. On the contrary, it could have seriously damaging consequences for the person harmed: First, it is likely that she will already have told her partner, on multiple occasions, how his actions have been harming her, but without any success. Telling him yet again in a RJ meeting is therefore unlikely be any more effective. Second, if she has not yet had the opportunity to tell her partner about the impact of his behaviour, or at least not in any detail, then there is a real danger that he might use this information as additional 'ammunition'. Now he knows exactly the kind of behaviours that will hurt her the most; and so, if she agrees to stay in the relationship, he could become far more effective in his control and abuse of her. ${ }^{15}$

\section{GENDER EQUALITY}

\subsection{Apologies}

$\mathrm{RJ}$ is premised on the assumption that all human beings are of equal intrinsic worth. The underlying message of moral harm or wrongdoing, however, is to deny this assumption. If you commit a wrongful act against me, you send me the message that I am 'less than' you, that I can be 'used for your purposes', that you 'do not deserve my respect as an equal'. ${ }^{16}$ One way of understanding the purpose of a RJ meeting, then, is to see it as enabling the person responsible to communicate to the person harmed that he no longer stands by these cruel and degrading messages. The role of the person responsible is to acknowledge, clearly and without qualification, that the person 
harmed is of equal intrinsic worth. This acknowledgement lies at the core of what it means to offer a genuine apology. ${ }^{17}$

The problem is that, in most cases, DV is motivated or justified by discriminatory and degrading views about women: that is, a man who inflicts DV will typically take the view that men are inherently superior to women and are therefore 'entitled' or 'authorised' to rule over or control them (e.g. to be the 'head of the house'). ${ }^{18}$ But then it follows that, if a man who has inflicted DV retains this view, then they cannot genuinely participate in a RJ process. Their apology, by definition, would be insincere.

As a response to this obstacle, it might be suggested that a RJ service could partner with a behaviour change program, so as to ensure that any sexist beliefs and attitudes are rectified prior to the RJ process. ${ }^{19}$ However, this kind of moral change is exceptionally difficult, and the evidence for effective and enduring transformation is not promising. ${ }^{20}$ There is even evidence that behaviour change programs can reinforce beliefs about male superiority:

\footnotetext{
"In cases where men's oppressive behavior is challenged, such as batterer intervention programs ... or prison antiviolence groups ... men often collaborate to outwit social workers and assert a right to control women. Inequality is thus reproduced when males uncritically affirm oppressive elements of other males' manhood acts or conspire to resist challenges to those acts. ${ }^{21}$
}

A far more significant obstacle that such programs face is the fact that gender equality is widely disputed at a societal level. This means that men who inflict DV can, and typically will justify or excuse their behaviour by appealing to values that are widely accepted in mainstream culture and religious communities. ${ }^{22}$ Behaviour change programs on their own cannot be expected to defeat or reverse this kind of systemic, cultural sexism. ${ }^{23}$ But then it follows, on both counts, that merely requiring a man who has inflicted DV to complete a behaviour change program prior to the RJ process will not, on its own, necessarily guarantee its safety or effectiveness.

\subsection{The Influence of Support Persons}

A related problem is that standard RJ conferences will invite the support persons of the person responsible to attend. The reason for doing so is that his family and friends are uniquely able to condemn his actions, whilst ensuring that he knows that they still love and respect him as a person - a process that John Braithwaite calls 'reintegrative shaming' ${ }^{24}$ But in DV cases, the family members and friends of a man who has inflicted DV will often hold similar beliefs and attitudes about the inequality of women; and so they are more likely to affirm his justifications and excuses - an outcome that would be diametrically opposed to the central purpose of a RJ process. A facilitator may be able to exclude his family members and friends from the meeting, but they cannot exclude them from his life. Their influence will be felt, whether they attend or not. Standard $\mathrm{RJ}$ processes are not equipped to address this issue. ${ }^{25}$ 
RJ conferences also invite the support persons of the person harmed, and this creates a similar issue. In many cultures and religious communities, a woman who separates from or divorces her husband is strongly condemned. She would thereby bring shame not only on herself, but on her wider family group. For this reason, the family and friends of a woman who has been harmed by DV can place a great deal of pressure on her to withdraw (or at least suppress) her accusations and be 'reconciled' to her abusive husband. ${ }^{26}$ The underlying assumption here is that women are not considered as equal to men, and so they should submit to and remain with their husband-even if he is violent. A facilitator might exclude such family members and friends from the process, but their influence will remain. So again, standard RJ processes on their own do not have the capacity to address this issue; and yet it clearly has the potential to undercut the restorativeness of the process. ${ }^{27}$

\section{RECONCILIATION}

\subsection{Moral Repair vs. Relationship Repair}

In the majority of cases that are referred to RJ programs, there is no pre-existing relationship between the participants. They may know of each other in a minimal sense (e.g. they live in the same area or go to the same school or workplace); but they are typically strangers. This has had a central impact on the way in which standard RJ processes have been designed. Specifically, the primary goal of a standard RJ process is to enable the participants to engage in the work of 'moral repair', but not 'relationship repair'. In other words, RJ is designed to enable the participants to engage in acts such as: the person who has caused harm taking responsibility for their actions and offering an apology; the person harmed saying how they were affected, responding to the apology, and so on. But this work of moral repair can be carried out even where the participants do not have a pre-existing relationship and do not intend to start one. The only relational connection that moral repair assumes is that each person is willing to acknowledge that they each share a common humanity. ${ }^{28}$ They can relate to each other on that basis, without needing to have (or have had) a personal or intimate relationship.

The problem is this: When the work of moral repair is carried out within the context of a pre-existing relationship, this is usually driven by a desire to engage in relationship repair. When people in a personal or intimate relationship have engaged successfully in the work of moral repair, they will tend to regard this as grounds for being reconciled to each other. In other words, when moral repair occurs in the context of a relationship, it is typically seen as more or less equivalent to relationship repair. But this has seriously detrimental and even dangerous consequences when it comes to the use of RJ in DV cases, as the following examples show.

First, in any DV case, the man who was responsible-and potentially some or all of both sets of support persons-will agree to take part in RJ for the sole purpose of 
bringing about reconciliation. This can be for cultural or religious reasons and/or to make sure he can avoid legal repercussions. The facilitators may caution the participants that reconciliation is not the primary aim of RJ, and that they should not feel pressured to re-start or continue the relationship. But given the close connection between moral repair and relationship repair, it will be difficult for the woman to resist the (often explicitly expressed) assumption that, in light of the moral repair work achieved in the RJ process, she no longer has any grounds for leaving her partnereven if that is the safest option for her. ${ }^{29}$

Second, in most RJ programs, the facilitators will generally expect to have only minimal contact with the participants after the RJ meeting. This is because it is assumed that the participants are unlikely to have anything to do with each other after the meeting, and so there will not be any ongoing relationship issues or long-term repair-work that may require the support and assistance of the program. However, if the woman who has been harmed is persuaded to return or stay with her partner as a result of the RJ process, then the work of moral repair is likely to be a long-term undertaking, given the potential for relapse. But RJ processes, as standardly designed and practiced, are not able to provide this kind of ongoing relational support and assistance. $^{30}$ Koss makes this point well in the following, where she distinguishes between the use of conferencing for DV and acquaintance rape:

\footnotetext{
"Because a batterer's purpose in using psychological and emotional abuse is often long term and related to coercing further behavior by the survivor, it is less amenable to external control by conference organizers. For those cases of acquaintance rape in which an ongoing intimate relationship is not an issue, good preconference preparation and consistently enforced rules of conduct for the conference itself could be expected to minimize the occurrence of further psychological and emotional harm to the survivor." ${ }^{31}$
}

It might be argued that this demand for post-meeting support is not consistent with a key principle of RJ, namely, that any ongoing work of moral or relational repair should be devolved to the participants' respective communities of care. This principle might be applied to the typical 'one-off' crimes or incidents that are referred to RJ programs. But it would be a serious mistake to suppose that it might be possible to devolve responsibility to communities of care to provide ongoing protection and support in cases of DV. As Julie Stubbs states:

\footnotetext{
"Outcome plans for domestic violence may require a significant commitment of resources over time in order to respond to a victim's concerns. For instance, . . . for community disapproval to be effective and to provide protection, it needs to be backed by extensive resources including programs for offenders, holding facilities and recourse to injunctions, curfews, and strong sanctions. Can the 'community of care' assembled for the restorative process sustain such demands? Who will monitor the outcome? Over what period? Restorative justice processes are said to engage the community in responding to the offending behaviour . . . . However, this appeal to community offers little real guidance as to mechanisms for accountability." 32
} 


\title{
5.2. Motivation for Staying
}

It is often suggested that one distinctive benefit of using RJ in at least some DV cases is that it can provide a non-separation option. Many women, it is argued, want to stay with their partners, but they just want the violence to stop. Yet most other DV interventions - whether criminal justice or informal - are strongly orientated toward facilitating or bringing about separation. ${ }^{33}$

\begin{abstract}
"Studies have repeatedly shown that people subjected to [Intimate Partner Violence] opt out of the legal system because they love their partners and want to maintain relationships with them. In a recent study of the Bennington, VT Integrated Domestic Violence Court, $70 \%$ of the couples who came through the system were either still involved in their relationships or planned to continue them ... The CLS's focus on punishment is inconsistent with that goal." ${ }^{34}$
\end{abstract}

So it could be argued that RJ might serve to honour and support a woman's decision to stay. ${ }^{35}$ The problem is that using RJ for this particular reason is fraught with complexities. For instance, there is strong evidence that women can choose to stay with a violent partner for reasons other than a desire to remain in a relationship with him. For example, they may not have the independent financial means to leave ${ }^{36}$; or they might feel that they or their children would be under significant risk of violent, even fatal repercussions ${ }^{37}$; or they may be under enormous pressure from their religious community, family members or cultural context. But if these externalities were removed, for instance, by sufficient legal aid, state-protection, adequate financial assistance, and the mobilisation of community support ${ }^{38}$, then - and only then - might it become clear as to whether a woman is genuinely free to decide whether or not stay with her partner. ${ }^{39}$

\footnotetext{
"Providing economic resources could help people subjected to [Intimate Partner Violence] to leave abusive relationships in which they would otherwise be entrapped. Justice could entail attempts to ensure people subjected to IPV have their basic economic needs met, without interference from their partners, so that their choices about the future of their relationships are not constrained by economic necessity." 40
}

In other words, a woman might agree to participate in RJ only because she feels that leaving the relationship — which is what she really wants - is still not a safe or realistic option. Far from providing a genuinely 'restorative' outcome, the RJ process would then only serve to prolong, if not intensify her entrapment within the abusive relationship. In such cases, the resources needed to organise a standard RJ process would be put to far better use if they were allocated instead to removing the externalities that are forcing her 'choice' to stay. ${ }^{41}$ 


\section{TYPES OF DOMESTIC VIOLENCE}

\subsection{Coercive control}

As a result of some innovative statistical analysis by academics Johnson and Stark, much of the relevant literature has come to identify three categories of DV or Intimate Partner Violence (IPV): namely,

(1) violence enacted in the service of taking general control over one's partner ('coercive control');

(2) violence utilized in response to coercive control ('violent resistance'); ${ }^{42}$

(3) violence that is not embedded in a general pattern of power and control, but is a function of the escalation of a specific conflict or series of conflicts ('situational couple violence'). ${ }^{43}$

One problem that these categories raise for RJ is this: Whilst situational couple violence is statistically the most common form of IPV ${ }^{44}$, coercive control is the type that most people think of when they hear the term 'domestic violence'. ${ }^{45}$ Indeed, it is cases involving coercive control that are most frequently referred to the police and/or DV support agencies. ${ }^{46}$ But DV referrals to RJ programs are most likely to come from criminal justice or DV support agencies. It follows that referrals to RJ are most likely to be cases involving coercive control. But, given the arguments above, these are precisely the kind of cases that standard RJ processes are not equipped to deal with safely and effectively. ${ }^{47}$

\subsection{Situational couple violence}

It might be argued that, whilst RJ should not be used in cases of coercive control, it may be appropriate for cases of situational couple violence. ${ }^{48}$ For instance, it was argued above that standard RJ processes are unlikely to be able to remove the deepseated, culturally reinforced sexism of abusers. But one 'finding' of the research that led to the categorisation above is that this level of misogyny applies more readily to cases of coercive control than situational couple violence:

\footnotetext{
“[M]ale perpetrators of [coercive control] have significantly more misogynistic attitudes than do nonviolent men, whereas perpetrators of situational couple violence have the same attitudes toward women as do nonviolent men .... Theoretically speaking, patriarchal traditions and structures, average sex differences in the use of violence, and average size and strength differences between men and women all suggest that in heterosexual relationships [coercive control] will be largely male-perpetrated. Empirically speaking, the evidence, both direct and indirect, confirms that [coercive control] is largely male-perpetrated and related to gender attitudes." ${ }^{49}$
} 
However, even if it were the case that $\mathrm{RJ}$ could address situational couple violence safely and effectively, this kind of case is unlikely to come to the attention of police or DV agencies. So it is unclear how cases of situational couple violence would be referred to a standard RJ program.

\subsection{Privatising $D V$}

One response to this objection might be to create voluntary referral pathways to RJ, thus avoiding the police or DV agencies. The eligibility criteria would be restricted to cases involving only situational couple violence. But there are two problems with this approach. First, there is a strong case for thinking that situational couple violence is not in fact gender symmetrical but is instead on a continuum with coercive control.

\footnotetext{
"We show that all domestic violence is gendered, not only the extreme forms, such as [coercive control]. The more serious (injurious) and frequent the domestic violence, the more gender asymmetrical. But even the less serious (noninjurious) and less frequent is gender asymmetrical. . . . [In other words] situational couple violence [and coercive control are not] stable types. We theorize these different patterns as steps in escalation of seriousness. Many households split after a limited number of acts of violence; those that do not could experience escalation to more frequent and serious violence." ${ }^{50}$
}

For instance, misogyny-like racism-can be so deep-seated that it issues in behaviour that is 'unintentionally' sexist. In other words, gender-based discrimination can be situated on a continuum from subtle insults to total subjugation. Thus, it may be that a conflict or a 'fight' (i.e. situational couple violence) was preceded by an ongoing pattern of misogynistic forms of subtle put-downs or micro-aggressions. ${ }^{51}$ These behaviours are typically ambiguous, unintentional and, as such, difficult to identify, even for the person harmed. But the cumulative impact is acutely hurtful and degrading, to the point where resistance or 'fight-back' becomes inevitable. It seems clear that the underlying cause of the conflict or 'fight', in such cases, is not gendersymmetrical: it is instead a consequence of the man's view-whether overtly acknowledged or not-about the inferiority or inequality of women. ${ }^{52}$ It is critically important that RJ recognises this continuum so that it does not 'domesticate' the violence or approach it as being gender-neutral. ${ }^{53}$ But then, as noted above, it is just as important to acknowledge that standard RJ processes do not have the capacity, on their own, to address the kind of masculinity that is premised on gender inequality; and so, just as with coercive control, it follows that $\mathrm{RJ}$ is not equipped to address the underlying causes of situational couple violence.

The second problem with creating informal referral pathways to RJ is this: if situational couple violence is on a continuum with coercive control-and so should still be classified and treated as DV-then it follows that there should be a public recognition of the seriousness of this kind of abuse. But whilst RJ is well-equipped to address private matters in the realm of moral repair, it is not capable of marking the 
seriousness of a crime in a public, societal matter. ${ }^{54}$ Only the criminal justice system is capable of this level of public, symbolic denunciation. As Tadros puts it:

"The criminal justice process has unique power to mark a public recognition of the wrongful nature of a particular kind of conduct and to stigmatize those who perpetrate that conduct. Taking domestic abuse outside the criminal justice system is likely to create or reinforce the perception that domestic abuse is less 'serious' than other kinds of assault, when what has been argued here is that domestic abuse is often very serious, and serious in a way that distinguishes it from other kinds of assault." ${ }^{\prime 5}$

It follows that referrals to RJ that by-pass the criminal justice system will have the effect of both minimising the seriousness of the harm that women experience in contexts of situational couple violence, and reinforcing the denial of gender equality that underpins this kind of violence. ${ }^{56}$

Notwithstanding these concerns about privatisation, it should be noted that there are significant objections to the criminal justice system's approach to DV, especially in relation to its tendency to discriminate against people of colour (and especially women of colour $)^{57}$, low-income and other minority groups; as well as its propensity to deal with cases of DV in a way that disempowers women, over-rides their 'voice', ignores their choices ${ }^{58}$, fails to prevent re-offending and indeed creates the conditions for continued DV when those responsible are released.

Indeed, it is for these very reasons that both support-agencies and women harmed by DV have been keen to explore alternatives to the criminal justice system ${ }^{59}$, or at least parallel or supplementary approaches such as restorative justice. ${ }^{60}$ However, as many have pointed out, the need for an alternative does not, in itself, warrant the use of RJ for cases of DV. The processes used must be 'fit for purpose', and the arguments above would strongly suggest that the most widely used 'standard' RJ processes would require significant re-design before they could be safely employed in this context. ${ }^{61}$

\section{A WAY FORWARD}

\subsection{Recommendations}

Given the number of risks and obstacles to using standard RJ processes to address DV, it might be thought that we should abandon this approach entirely. However, the consistent refrain in this paper has been that RJ processes could potentially be revised or adapted to suit a DV context. It would not be possible, nor desirable, to set out such a 'revised version' here, at least not in any detail. That task, as we shall see, must be left to the individuals and communities who are hoping to provide and use such a service. However, it may be helpful to put forward three recommendations. 


\subsection{Action-Research}

The use of RJ to address DV has now become relatively widespread and appears to be increasing. For example, a report published in 2010 identified RJ or mediation programs that were accepting DV cases in the US, UK, Austria, Belgium, Finland, Germany, Romania, Jamaica, Columbia, Australia, New Zealand, the Gambia, South Africa, and Thailand. ${ }^{62}$ However, a 2017 survey of evaluations found that the evidence for the effectiveness of this application of RJ is not substantial. Most programs have been able to identify cases in which the participants felt 'satisfied' with the outcome, and even reports that the violence has stopped or decreased following a RJ process. ${ }^{63}$ However, the lack of practice-uniformity and case-types across programs and locations, as well as small sample sizes, mean that no general conclusions can be legitimately drawn. ${ }^{64}$ Moreover, it is not possible to generalise from the effectiveness of RJ in nonDV cases, given the distinctiveness of the context and type of harm caused by DV.

It follows from this that, whilst there is some indication that RJ processes can be used safely and effectively in cases of DV, any new approach cannot merely follow the example of previous or existing programs. Lessons can be learnt, of course; but if a new application of RJ principles to cases of DV is to be developed, then it must, from the outset, build in a rigorous action-research framework - not merely to evaluate longterm outcomes, but also to ensure that practices and procedures are adjusted, improved and refined as and when the evidence demands. As Ptacek states:

"Given the thinness of the evaluation research on RJ and IPV, there is much to be done. Clearly, there are many existing practices that need rigorous follow-up research. This research should go beyond simple measures of recidivism and victim satisfaction to explore- - using both qualitative and quantitative methods - the experience of the practices upon survivors, offenders, and their families [and practitioners], both in the short and the long term." ${ }^{65}$

\subsection{Consultation and Collaboration}

The available research indicates that those programs which have reported some success were not, in fact, straightforward applications of standard RJ processes to DV cases. Instead, they had three distinctive features:

a) they were co-designed and implemented in collaboration with multiple relevant stakeholders;

b) they combined feminist principles with restorative practices; and

c) they had a distinctive focus on the needs of minority groups-especially indigenous communities, people of colour, immigrants, people from a culturally and linguistically diverse background, LGBTIQ communities, and so on. 
For instance, one of the most effective uses of a restorative approach to DV was a 'family group decision making' program in North America, set up and evaluated by Joan Pennell and Gale Burford. The design phase involved wide-ranging consultations and close collaboration with women's advocates, child and youth advocates, offender programs, academic researchers, the police, government officials from social services, corrections, victim services and prosecution. ${ }^{66}$

Another effective program designed for cases of sexual assault ${ }^{67}$ is the RESTORE ${ }^{68}$ Program in Arizona, which was developed by the psychologist Mary Koss in extensive consultation and collaboration with a wide range of stakeholders:

\footnotetext{
"Cognizant of the importance of developing such a program with input from and accountability to feminist advocates and people of color, this program was developed in collaboration with feminist organizations, criminal justice officials, and leaders from communities of color in Pima County. Members of these organizations, agencies, and communities not only participated in focus groups but also are players in the infrastructure of RESTORE. In addition, the program operates under the aegis of the local sexual assault center, ensuring feminist advocates' ongoing oversight and input throughout the process." 69
}

A third example is the 'Cultural Context Model' (CCM), which was developed by the Institute for Family Services in Somerset, New Jersey. This program was explicitly designed to address the distinctive cultural differences and needs of people harmed by DV from marginalised groups. The program's design and implementation were based upon a systemic cultural analysis and the close involvement of relevant communities, both of which are key drivers of its effectiveness:

\footnotetext{
"The CCM approaches intervention with batterers and their families from a perspective that acknowledges a multilayered experience of culture. More specifically, the treatment approach requires accountability from batterers and supports the empowerment of victims and children at the same time as it recognizes the impact of a number of social forces related to culture and cultural differences on communities, families, and individuals. These forces include such realities as sexism, racism, and heterosexism, as well as experiences with immigration, colonization, and capitalism." 70
}

A second recommendation for charting a way forward, therefore, would be to begin any development process by engaging in a wide-ranging consultation with external and internal stakeholders. It must also ensure that every stage-planning, design, implementation and evaluation - are all informed and guided by a feminist analysis of the nature and causes of DV. ${ }^{71}$

\subsection{Transformative Fustice}

The main reason for not abandoning RJ entirely in cases of DV is that there are a number of unique benefits that a restorative approach can bring about. These are usefully listed by Daly and Stubbs in the following: 
- Victim voice and participation. Victims have the opportunity to voice their story and to be heard. They can be empowered by confronting the offender, and by participating in decision making on the appropriate penalty.

- Victim validation and offender responsibility. A victim's account of what happened can be validated, acknowledging that she is not to blame. Offenders are required to take responsibility for their behaviour, and their offending is censured. In the process, the victim is vindicated.

- Communicative and flexible environment. The process can be tailored to child and adolescent victims' needs and capacities. Because it is flexible and less formal, it may be less threatening and more responsive to the individual needs of victims.

- Relationship repair (if this is a goal). The process can address violence between those who want to continue the relationship. It can create opportunities for relationships to be repaired, if that is what is desired. ${ }^{72}$

One key element missing from this list, however, is the need to take into account the structural inequalities and conditions of subordination that both cause and are caused by DV. This will primarily include gender inequality, as manifested in the surrounding culture and/or communities, and in the personal beliefs and attitudes of individuals who are involved in the process. But it should also include any other structural inequality or experience of subordination that might have a bearing on the case-either in terms of understanding proximate causes and influences but also in terms of identifying long-term solutions. ${ }^{73}$

For example, Donna Coker has argued that a restorative approach to DV would be far more powerful if it could enable a person who inflicts DV to link his own experience of feeling subjugated by racial or economic inequality to the harm he is causing to his partner and the way in which his behaviour is driven by his beliefs about gender inequality. In addition, it would be considerably more effective, in the long-term, if it could somehow galvanise their respective families and the local community into doing what it can to acknowledge and address the oppression caused by both types of inequality. ${ }^{74}$ Similarly, Coker argues that any service that seeks to address DV in a restorative manner must address, so far as possible, the material and social externalities that constrain women's choices - and in a way that allows for (and is supportive of) her decision to remain with her partner, or at least within her community. ${ }^{75}$

Coker suggests that these additions would offer "the possibility of transforming communities as well as interpersonal relationships". ${ }^{76}$ The aim would not be to 'restore' things to how they were, since things were never 'just' to begin with ${ }^{77}$ Instead, the objective would be to identify, confront and change the structures and beliefs that are causing (and being caused by) these inequalities and conditions of oppression. 
In other words, whilst this approach should draw on RJ principles, both the language of 'restoration' and the way in which RJ processes are standardly practiced may be counter-productive and potentially misleading. For this reason, Coker distinguishes this approach from standard RJ processes, by calling it 'Transformative Justice'. ${ }^{78}$ Given the way in which this approach is likely to resolve many of the issues that have been raised above, it is therefore recommended that, if any program is developed so as to address DV in a way that can achieve the multiple benefits described above, then the broader concept (and even the terminology) of 'Transformative Justice' be used.

\section{Endnotes}

${ }^{1}$ I do not include under the 'restorative justice' rubric any process that is primarily designed to resolve a conflict or dispute between 'moral equals', such as mediation or ADR (alternative dispute resolution). Such processes would never be appropriate for domestic violence (or, indeed, any other kind of harm or wrongdoing), as I have argued elsewhere. See Brookes, D. R. and McDonough, I. (2006). The Differences between Mediation and Restorative Justice/Practice.

${ }^{2}$ Three qualifications are needed here: First, I am not claiming that 'standard' RJ processes have never been used to address domestic violence in a way that was safe and effective. However, the evidence to date would suggest that, on closer inspection, it is likely that these cases only managed to avoid the kind of concerns raised in this paper by making significant amendments to the normal practice (see Section 7). Second, I am not suggesting that every single RJ service currently operating will (or can) only deliver the kind of RJ processes that I am calling 'standard'. However, most RJ services do routinely deliver processes that incorporate at least one or more of the features that I identify as 'standard'; and so, if the arguments in this paper are sound, then it would be, to that extent, problematic for them to take on DV cases. Finally, RJ processes did not evolve in a vacuum: there are historical and pragmatic reasons for their 'standardisation'. First, RJ services were originally designed to take referrals from the criminal justice system (e.g. as a diversion from prosecution), and so, as a consequence, took on a range of procedural restrictions, including a focus on the harm caused by individual crimes or offences, rather than cumulative harms. Many of these restrictions have since been replicated in non-justice or extralegal contexts, largely due to the effect of using procedural manuals and training events that were intended for the original criminal justice context. Second, RJ services are typically under significant pressure to use 'standardised' processes as a result of inadequate funding, time limitations, evaluation methodologies, and best practice considerations.

${ }^{3}$ The gendered language and recommendations in this paper reflect the evidence that the vast majority of DV is committed by men against women (see, e.g. https://www.who.int/news-room/factsheets/detail/violence-against-women). However, this is not intended in any way to diminish or overlook the pain and suffering experienced when DV is committed by women against men or within LGBTIQ relationships. The arguments of this paper still apply mutatis mutandis. If RJ processes are to be used in these contexts, they will require significant adaptation - and mostly along the same lines advocated here.

${ }^{4}$ As with the criminal justice approach, the focus of a standard RJ process can extend to (a) multiple crimes, if they occur within the one incident (e.g. robbery and assault); and (b) multiple offenders, if they are all involved in the one incident (e.g. gang-related violence). But these are, of course, not exceptions to the general rule.

${ }^{5}$ See, e.g.: "It has generally been regarded as an impediment in prosecution that the courts are unable to 'see' the systematic nature of [domestic] abuse for the reason that any instance of violence is often prosecuted either in isolation or as one of a short series of instances. This may lead to lenient sentences where the particular instance of violence that results in prosecution and conviction is not very severe in isolation, but appears much more severe in context." Tadros, V. (2005). The Distinctiveness of 
Domestic Abuse: A Freedom Based Account. Louisiana Law Review, 65(3), 989-1014: pp. 995-96; " $[\mathrm{O}]$ ne type of abuse rarely occurs in isolation of others, [and] a single abusive experience is often the exception rather than the norm .... [M] ore experiences of abuse, whether repetition of the same type, differing types, or a combination of both, result in health outcomes that differ from those associated with an isolated experience of abuse" Scott-Storey, K. (2011). Cumulative Abuse: Do Things Add Up? An Evaluation of the Conceptualization, Operationalization, and Methodological Approaches in the Study of the Phenomenon of Cumulative Abuse. Trauma, Violence, E Abuse, 12(3), 135-150: p. 135, 137; “[T] he hallmark of women's physical abuse is frequent, but predominantly minor assault extending over a considerable period and with a cumulative impact on women's health that is unparalleled among other classes of assault victims. Partner assault is limited to isolated incidents in only a tiny proportion of cases ...." Stark, E. (2010). Do Violent Acts Equal Abuse? Resolving the Gender Parity-Asymmetry Dilemma. Sex Roles, 62(3), 201-211: p. 203; "'[M]odern restorative justice models were designed to deal with isolated crime events between strangers. However, in contrast to the archetypal crime 'event,' intimate partner violence tends to include 'a range of behaviours and coercive tactics not all of which are immediately discernible to others; it is often repetitive, meaningful and strategic' (Stubbs, 2002, p. 43)." Cheon, A. and Regehr, C. (2006). "Restorative Justice Models in Cases of Intimate Partner Violence: Reviewing the Evidence", Victims E Offenders, 1(4), 369-394: p. 384.

${ }^{6} \mathrm{Cf}$. "Domestic violence offenders often apologize for their violence afterward and ask for forgiveness from and reconciliation with their partner. Frequently, truly caring for and wishing to continue in their relationship with the offender, survivors are often persuaded by these apologies that he is truly remorseful and dedicated to change. Although these offenders may often feel transitory remorse for their actions and think that they will not engage in future battering, when these apologies are echoed following second, third, or fourth incidents of violence, their function in manipulating the survivor to return to the relationship becomes patent." Koss, M.P. (2014). The RESTORE program of restorative justice for sex crimes: Vision, process, and outcomes. Fournal of Interpersonal Violence, 29(9), 1629-1660: p. 714; "[T]he skill of contrite apology is routinely practiced by abusers in violent intimate relationships" Acorn, A. (2004). Compulsory Compassion: A Critique of Restorative fustice. Vancouver: UBC Press: p. 73.

7 This point is made repeatedly in the literature. See, e.g., Stubbs, J. (1995). Communitarian Conferencing and Violence Against Women: A Cautionary Note. In M. Valverde et al (eds) Wife Assault and the Canadian Criminal Fustice System. Centre of Criminology, University of Toronto; Stubbs, J. (1997). Shame, Defiance and Violence Against Wome. In Cook, S. and Bessant, J. (eds) Women's Encounters with Violence: Australian Experiences. London: Sage; Stubbs, J. (2002). Domestic Violence and Women's Safety: Feminist Challenges to Restorative Justice. In Strang, H. and Braithwaite, J. (eds) Restorative fustice and Family Violence. (Melbourne: Cambridge University Press); Stubbs, J. (2003). Sexual assault, criminal justice and law and order. Women against Violence: an Australian Feminist Fournal, vol.14; Coker, D. (1999). Enhancing Autonomy for Battered Women: Lessons From Navajo PeaceMaking. UCLA Law Review vol. 47 no. 1.; Coker, D. (2002). Transformative Justice: AntiSubordination Practices in Cases of Domestic Violence. In Strang, and Braithwaite, 2002; Coker, D. (2001). Crime Control and Feminist law Reform in Domestic Violence Law: A Critical Review. Buffalo Criminal Law Review vol.4, no. 801; Busch, R. (2002). Domestic Violence and Restorative Justice Initiatives: Who Pays if We Get it Wrong?. In Strang, and Braithwaite, 2002; Cossins, A. (2008). Restorative justice and child sex offences: the theory and the practice. British fournal of Criminology, vol. 48 , no. 3.

${ }^{8}$ Cf. "There is an emphasis on offender apologies in RJ that can create particular problems for addressing IPV, in which false and manipulative apologies are commonplace." Ptacek, J. (2017). Research on Restorative Justice in Cases of Intimate Partner Violence. In Preventing intimate partner violence. Edited by Claire M. Renzetti, Diane R. Follingstad and Ann L. Coker. Bristol University Press. pp. 159-184: p. 164.

${ }^{9}$ Martin, P. (1996). "Restorative Justice: A Family Violence Perspective," Social Policy fournal of New Zealand/Te Puna Whakaaro (6): p. 9.

${ }^{10}$ As recommended in the following: "In New Zealand, one philosophical problem has been the claim that any member of the community can act as a facilitator (Mansill, 2000). This claim is dangerous in a domestic violence context where the risk of further violence is high and the need for expertise in 
handling issues of violence, relationships and victimization is essential. There must be initial training and annual up-skilling requirements in the area of domestic violence for anyone who acts as a facilitator in mediation or restorative justice conferences dealing with domestic violence, either as a primary or backdrop issue." Busch, R. (2002). Domestic Violence and Restorative Justice Initiatives: Who Pays if We Get it Wrong?. In Strang, H. and Braithwaite, J. eds. Restorative justice and family violence. Cambridge; Port Melbourne, Vic.: Cambridge University Press: p. 229.

11 "The simple and real fear of future violence alone may cause a victim of ongoing violence to accede to terms to which she would not otherwise agree. Thus, these power dynamics can skew bargaining power in a community conference and thus yield an agreement that does not adequately or accurately reflect the survivor's interests or wishes." Koss, 2014: p. 713.

${ }^{12}$ E.g. "Women will not necessarily want or know how to reveal the true state of their relationship . .. . Coercive control changes their worldview and how they feel about themselves and they may fear retaliation." Pitman, T. (2017). Living with Coercive Control: Trapped within a Complex Web of Double Standards, Double Binds and Boundary Violations. The British Fournal of Social Work, 47(1), 143-161: p. 159.

13 "One of the most insidious effects of family violence is the damage it can do to a victim's perceptions over time - they often lose confidence in their own perception of reality. Some become habituated to their partner's behaviour, seeing it as normal or as something they deserve. This can lead victims to ignore or play down the violence. However, the behaviour is still violent or controlling, even if the victim doesn't recognise this." NZ Ministry of Justice. (2018). Restorative fustice: practice standards for family violence cases: p. 18.

${ }^{14} \mathrm{Cf}$. "Some proponents of restorative justice argue that it is 'possible to develop strategies to address power imbalances' within sessions so that women's voices will be heard . . .; but, while these techniques may work in the moment, it is doubtful that they will have a lasting impact on deeply entrenched patterns of control. While, admittedly, this may not be the principle goal in a single restorative justice session, the problem lies in the illusion of enhanced power that these techniques may create in the minds of women, who then enter into agreements under this false perception of increased power." Cheon and Regehr, 2006: p. 380.

${ }^{15}$ Cf. Martin, 1996: pp. 9-10.

${ }^{16}$ Cf. "[Someone] fails to treat me with respect if she makes no effort to hide her disinterest in, or contempt for, my feelings. When she treats me this way, she implies that my concerns, my feelings, my point of view do not matter, that is, that I have no intrinsic value, after all." Buss, S. (1999). Appearing Respectful: The Moral Significance of Manners. Ethics, 109, 4, 795-826: p. 804. Again, "One reason we so deeply resent moral injuries done to us is not simply that they hurt us in some tangible or sensible way; it is because such injuries are also messages-symbolic communications. They are ways a wrongdoer has of saying to us, 'I count but you do not,' 'I can use you for my purposes,' or 'I am here up high and you are there down below.' Intentional wrongdoing insults us and attempts (sometimes successfully) to degrade us - and thus it involves a kind of injury that is not merely tangible and sensible. It is moral injury, and we care about such injuries." Murphy, J. (1988). Forgiveness and Resentment. In Murphy, J. and Hampton, J. Forgiveness and Mercy. Cambridge: Cambridge University Press: p. 25.

17 "[Repentance] is surely the clearest way in which a wrongdoer can sever himself from his past wrong. In having a sincere change of heart, he is withdrawing his endorsement from his own immoral past behavior; he is saying, 'I no longer stand behind the wrongdoing, and I want to be separated from it. I stand with you in condemning it.' Of such a person it cannot be said that he is now conveying the message that he holds me in contempt." Murphy (1988): p. 26. Cf. "[A]pologies represent a splitting of the self into a blameworthy part and a part that stands back and sympathizes with the blame giving, and, by implication, is worthy of being brought back into the fold." Goffman, E. (1971). Remedial Interchanges. In Relations in Public: Microstudies of the Public Order. New York, NY: Basic Books, 95187: p. 113.

${ }^{18}$ E.g. "The women [in our study] described their partners as having an attitude of superiority and treating them as if they were inferior in comparison. They felt reduced to an extension and a possession of their partner. Jessica and Genevieve conveyed the sense of being owned and this was common to all 
the women who participated in the study: 'I was not a person to him . . . I was there for his purposes and his purposes only. I was a commodity '(Jessica, P2). 'I felt owned . . . when I look back that's really how it was. . . (Genevieve, N).” Pitman, T. (2017). Living with Coercive Control: Trapped within a Complex Web of Double Standards, Double Binds and Boundary Violations. The British fournal of Social Work, 47(1), 143-161: p. 149. Again, "Domestic violence is . . a cause and consequence of gender inequality." Walby, S., \& Towers, J. (2018). Untangling the concept of coercive control: Theorizing domestic violent crime. Criminology \& Criminal fustice, 18(1), 7-28: p. 7.

${ }^{19}$ See, e.g.: "Intimate partner violence is rarely a 'one off' event. Offenders are usually so entrenched in their cognitive distortions, beliefs and behaviours that they're unlikely to be able to fully accept responsibility and partake respectfully and safely in a restorative justice conference without minimising or justifying their behaviour, or subtly blaming the victim. However, if the offender engages in a behaviour change programme: there is more chance the offender will engage in the restorative process; the victim is at less risk of repeat victimization; the potential for positive outcomes from the restorative justice conference is enhanced." NZ Ministry of Justice, 2018: p. 35.

${ }^{20}$ This is not, of course, to suggest that behaviour change programs are uniformly ineffective: there has been significant, enduring change for some participants. It should also be noted that some researchers have argued that the lack of widespread success may be partly due to the design flaws or practice inadequacies of behaviour change programs. See, e.g., Schrock, D. P. and Padavic, I. (2007). Negotiating Hegemonic Masculinity in a Batterer Intervention Program. Gender and Society, 21(5), 625649; Schrock, D., McCabe, J., \& Vaccaro, C. (2018). Narrative Manhood Acts- Batterer Intervention Program Graduates' Tragic Relationships. Symbolic Interaction, 41(3), 384-410; Morrison, P. K., et.al. (2017). Elements needed for quality batterer intervention programs: Perspectives of professionals who deal with intimate partner violence. Fournal of Family Violence, 32(5), 481-491.

${ }^{21}$ Schrock, D. and Schwalbe, M. (2009). Men, Masculinity, and Manhood Acts. Annual Review of Sociology, 35, 277-295: p. 288.

22 "John Braithwaite argues that reintegrative shaming, of the kind proposed by some restorative justice advocates, requires that the law in question 'represent a clearly majoritarian morality' . . . but as Braithwaite and Daly note, ' $[\mathrm{f}] \mathrm{ew}$ societies ... contain a majoritarian masculinity that sets its face against violence' . . . P Polls that show significant opposition to domestic violence are promising . . . but such research does not capture the degree to which people are sympathetic to the 'the hapless man who must defend against a nagging, shrewish woman". . or the cuckold husband who must defend his honour . ... Additionally, people often fail to condemn non-violent controlling behaviours such as threats to take children, control of money, isolation of the woman, and extreme jealousy . ..." Coker, 2002: p. 139.

${ }^{23}$ See, e.g., "'You can go to a two-hour [behaviour change] session and have as many 'breakthroughs' as you like,' said Elena Campbell, who runs a program of family violence research projects at the Centre for Innovative Justice at RMIT University. 'But then you'll walk out and all the messages about masculinity and your role [as a male] in society are reinforced as soon as you get on the bus or turn on the TV. If you've still got a violence-supporting peer group.' Ms Campbell said, 'then any progress you've made . . . in that isolated bubble is potentially going to be undone." Gleeson, Hayley (25 Nov 2018). The only way violent men can change is if they want to. (ABC) https://www.abc.net.au/news/2018-11-24/for-violent-men-behaviour-change-programs-can-be-lifechanging/10509934. See also: Vecina, M. L. (2018). How Can Men Convicted of Violence Against Women Feel Moral While Holding Sexist and Violent Attitudes? A Homeostatic Moral Model Based on Self-Deception. American fournal of Men's Health, 12(5), 1554-1562; Vecina, M. L., Chacón, F., \& Pérez-Viejo, J. M. (2015). Moral Absolutism, Self-Deception, and Moral Self-Concept in Men Who Commit Intimate Partner Violence: A Comparative Study With an Opposite Sample. Violence Against Women, 22(1), 3-16; Vecina, M. L., \& Marzana, D. (2016). Always looking for a moral identity: The moral licensing effect in men convicted of domestic violence. New Ideas in Psychology, 41, 33-38.

24 " [E]vidence from restorative justice conferences is that only disapproval communicated by people the offender most loves is effective in inducing remorse." Braithwaite, J. (2018). Minimally sufficient deterrence. Crime and Fustice, 47(1), 69-118: p. 85. See also Braithwaite, J. (1989). Crime, shame and reintegration. Cambridge: Cambridge University Press; and Braithwaite, J. \& Mugford, S. (1994). 
Conditions of successful reintegration ceremonies: dealing with juvenile offenders. The British fournal of Criminology, 34 (2), 139-171.

${ }^{25}$ E.g.: "The Hitting Home report provided some disturbing evidence about attitudes towards family violence which are still held by some members of the community. While the men interviewed tended to reject the use of physical force in families, a significant number said that women are to blame for being hit in some circumstances. In the case of eleven out of twenty possible circumstances, at least a fifth of the men blamed the woman alone for the man hitting her and, in one circumstance, nearly half the men blamed the woman alone." Martin, 1996: p. 6.

${ }^{26}$ E.g.: "[I[n many Native American communities, [restorative justice] models are often pushed on domestic violence survivors in order to pressure them to 'reconcile' with their families and 'restore' the community without sufficient concern for their personal safety.”. Smith, A. (2010). Beyond restorative justice: Radical organizing against violence. In J. Ptacek (Ed.), Restorative justice and violence against women (pp. 255-278). New York: Oxford University Press: p. 259.

${ }^{27}$ The NZ practice standards for the use of RJ recognize that "People who use family violence can be incredibly persuasive and subtle in the ways they downplay, deny, justify, and rationalise their behaviour ... [and will often] attempt to find common agreement with their supporters and/or with facilitators." But they also claim that "[s]killed and experienced facilitators can identify invitations to collude and use good practice to respond in ways that address offenders' implicit beliefs and violencesupporting narratives." NZ Ministry of Justice, 2018: p. 18.

${ }^{28}$ For more on the nature of moral repair, see Brookes, Derek R. (2019). Beyond Harm: Toward fustice, Healing \& Peace. Relational Approaches.

${ }^{29}$ For example, in 1999, Donna Coker published an important study of Navajo Peacemaking - an indigenous circle process-as it was applied to cases of IPV. She reported that some women were assaulted just after participating in a Peacemaking session. Coker, 1999: p. 82.

${ }^{30}$ Thus the point made in the following is correct, but it is not clear that a RJ process can prevent this kind of pressure, for the reasons given above: "Great care needs to be taken that restorative justice techniques do not contain the implicit message that reconciliation between the parties is the aim. Victims of family violence get enough pressure to stay with abusive partners without receiving more of it from the justice system to which they have turned for help and safety." Martin, 1996: p. 9.

${ }^{31}$ Koss, 2014: p. 712.

${ }^{32}$ Stubbs, 2002: p. 51-52. Cf. "As a group, [victims of intimate partner violence] tend to lack support networks or friends, which may be a direct result of either the controlling tactics of their partner, or the specifics of the offense itself . . . Morris and Gelsthorpe suggest that in these instances 'it might be possible for lay advocates (such as refuge workers) to support the women through the process' (2000, p. 424). However, the protracted nature of violent relationships, the lengthy process of healing, and ongoing safety issues seriously bring to question whether or not it is adequate to provide a victim with short-term support while she makes an agreement that has lasting consequences." Cheon \& Regehr, 2006: p. 386.

${ }^{33} \mathrm{Cf}$. "[W] hile wanting the violence to stop and seeking accountability from the perpetrator, some victims of family violence may wish to remain on reasonable or even intimate terms with the perpetrator, objectives which may be alien to a system that primarily aims to achieve and maintain separation of the parties." Royal Commission into Family Violence, 2016: p. 136; again, "The [RJ] process can address violence between those who want to continue the relationship. It can create opportunities for relationships to be repaired, if that is what is desired." Daly, K. and Stubbs, J. (2006). Feminist engagement with restorative justice. Theoretical Criminology, 10(1), 9-28: p. 18; "[L]aw-trained professionals tend to overemphasize legal courses of action and often believe that women will be safer if they separate and if legal proceedings are initiated", Coker, 1999: p. 68.; "Separation-based law and policy responses to domestic violence largely lack such nuance, however. Instead, such policies reflect a normative choice by the state that relationships between women subjected to abuse and men who are abusive are better destroyed than preserved. Hesitation or unwillingness to end a relationship means that the woman is being coerced, threatened, or controlled; from the feminist perspective, such women 
might be accused of 'false consciousness'." Goodmark, L. (2012). A Troubled Marriage: Domestic Violence and the Legal System. New York University: p. 100.

${ }^{34}$ Goodmark, L. (2017). Justice as a Tertiary Prevention Strategy. Preventing intimate partner violence (1 ed., pp. 185-208). Bristol University Press: p. 196.

${ }^{35} \mathrm{Cf}$. "The task, then, is to create a diversity of options, legal and non-legal, for women subjected to abuse - some that offer (but do not require) separation, and others that are available to women who choose not to separate. In so doing, we must change the philosophical orientation of our system from one that makes separation a cultural imperative to one that sees separation as one option among many." Goodmark, 2017: p. 203.

36 "For both employment status and housing tenure status, victims of domestic violent crime are more likely to have access to fewer economic resources compared to the overall population." Walby and Towers, 2018: p. 21;

${ }^{37}$ E.g. "Kelly, stayed with her husband to protect herself and her children until he was removed from the home by police arrest. He was never violent toward her but she feared he would kill her if she left: 'I was trapped in a situation where I wouldn't have gotten out safely. . . [Staying was] better than the unknown of, you know, I'm gonna get shot in the parking lot or stalked'." Crossman, K. A. and Hardesty, J. L. (2018). Placing Coercive Control at the Center: What Are the Processes of Coercive Control and What Makes Control Coercive? Psychology of Violence, Volume 8(2), March 2018, pp. 196206: p. 203.

${ }^{38}$ See, e.g, "[There are] myriad ways in which women attempt to organize both formal and informal resources [e.g. family, church, friends] to foster more choices in their lives and to increase their safety". Coker, 1999: p. 68, n.335.

39 "Some may argue that the contextual factors that prevent women from wanting to separateeconomics, family and community support, and immigration concerns, for example-are simply additional problems for the state to solve, but not reasons to justify decreasing our reliance upon separation-based policies. Until such time as the state is able to remove all of those constraints, however, we must accept that these are the contexts within which women make decisions about separation, and that separation serves many of them poorly, if it serves them at all." Goodmark, 2012: p. 104-5.

${ }^{40}$ Goodmark, 2017: p. 203.

${ }^{41} \mathrm{Cf}$. "Massive cuts to legal aid have pushed many women into informal processes and some women into making poorly framed and unworkable agreements around domestic violence and children, which are often breached ...." Stubbs, 2008: p. 59.

42 "In about two-thirds of cases of heterosexual intimate terrorism, the woman victim responds at some point with violence of her own. In most cases, she soon turns to other tactics to reduce the violence or escape the relationship. Compliance is often the first tactic, hoping to mitigate the violence until she can disentangle herself from the web of constraints with which he controls her. But these women are resourceful and most of them do eventually escape ... " Johnson, 2017: p. 158.

${ }^{43}$ Stark, E. (2007). Coercive Control. New York: Oxford University Press, and Johnson, M.P. (2008). A Typology of Domestic Violence. Boston, MA: Northeastern University Press.

${ }^{44}$ Johnson, M. P. (2006). Apples and Oranges in Child Custody Disputes- Intimate Terrorism vs. Situational Couple Violence. Fournal of Child Custody, 2(4), 43-52: p. 46.

${ }^{45}$ Johnson, 2006: p. 45.

${ }^{46}$ Johnson, M. P. (2017). A Personal Social History of a Typology of Intimate Partner Violence. fournal of Family Theory \& Review, 9(2), 150-164: p. 158.

47 "In cases of coercive control victim-offender mediation can be dangerous . . . ." Frost, L. et al (2013). Restorative Justice in Cases of Domestic Violence Best practice examples between increasing mutual understanding and awareness of specific protection needs. European Commission Directorate: p. 10; "[T] he common denominator of coercive control abuse cases was that the techniques used by abusers were sophisticated and often nuanced. This highlights the difficulty in both understanding and working with coercive control when professional systems are geared up to deal with single, unambiguous incidents of physical violence ...." Brennan, et. al. 2018: p. 5. 
${ }^{48}$ E.g. "in case of situational violence the use of RJ/mediation can turn out to be helpful and effective, especially when children are involved. . . . although this is rarely said explicitly - VOM opponents usually think of victims of [coercive control], not of situational couple violence" Frost, L. et al, 2013: p. 10-11.

${ }^{49}$ Johnson, 2006: p. 49.

${ }^{50}$ Walby, S., \& Towers, J. (2018). Untangling the concept of coercive control: Theorizing domestic violent crime. Criminology \& Criminal fustice, 18(1), 7-28: p. 25, 14.

51 "Broadly stated, microaggressions are subtle acts of bias that reflect a structural form of oppression toward a specific group of people, such as racism, transphobia, or sexism. . . Microaggressions are the behavioral consequence of an agent's implicit bias against a structurally oppressed group. These subtle insults are predominantly unintentional (that is, they are not usually the product of conscious action). Due to their subtlety, it is often ambiguous as to whether an act was in fact microaggressive, making them rather hard to identify or point out to others". Friedlaender, C. (2018). On MicroaggressionsCumulative Harm and Individual Responsibility. Hypatia, 33(1), 5-21: p. 6. Cf. Swim, J. K. and Cohen, L. L. (1997). Overt, Covert, and Subtle Sexism. Psychology of Women Quarterly, 21(1), 103; Wang, J., Leu, J. and Shoda, Y. (2011). When the Seemingly Innocuous "Stings"- Racial Microaggressions and Their Emotional Consequences. Personality and Social Psychology Bulletin, 37(12), 1666-1678; McTernan, E. (2018). Microaggressions, Equality, and Social Practices. Fournal of Political Philosophy, 26(3), 261-281.

${ }^{52}$ As Andersen points out: "Miller and White's (2003) analysis of gender and violence among dating youths largely describes violence that would be categorized as fights or assaults using [the definition of situational couple violence]. However, Miller and White clearly show that these types of violence stem from and reproduce inequalities of gender that make women and men unequal in the context of heterosexual relationships." Anderson, K. L. (2009). Gendering Coercive Control. Violence Against Women, 15(12), 1444-1457: p. 1453. Reference: Miller, J., \& White, N. (2003). Gender and relationship violence: A contextual examination. Criminology, 41, 1212-1248.

53 'Feminist critics also worry that processes like conferencing will 'domesticate' the violence ...., couching it as mere conflict or as centred in unique relationship dynamics rather than as the result of the batterer's struggle to dominate his partner." Coker, 2002: p. 131.

54 "[C]rime has a societal dimension, as well as a more local and personal dimension. The legal system focuses on the public dimensions; that is, on society's interest and obligations as represented by the state. However, this emphasis downplays or ignores the personal and interpersonal aspects of crime. By putting a spotlight on and elevating the private dimensions of crime, restorative justice seeks to provide a better balance in how we experience justice." Zehr, H. (2003). The Little Book of Restorative Fustice. Intercourse, PA: Good Books: p. 12; and again, "[T[he use of restorative justice processes does not signify the trivialization of any crime: the criminal law remains as a signifier and denouncer. In addition, however, restorative justice advocates believe that the offender's family and friends are by far the most potent agents to achieve this objective of denunciation. In the context of men's violence against their partners, denouncing the violence in the presence of the abuser's family and friends means that the message is loud and clear for those who matter most to him." Morris, A. (2002). Critiquing the Critics: A Brief Response to Critics of Restorative Justice. The British Fournal of Criminology, 42(3), 596-615: p. 603. It is important to note here that such claims as to the superiority of RJ over the criminal justice system (CJS) with respect to 'denunciation' turn on a false comparison. There is no single 'objective of denunciation', the achievement of which both the CJS and RJ are competing to fulfil. Rather, there are two different kinds of denunciation required: one is public, the other is private. The CJS is designed to achieve the former, RJ the latter.

${ }^{55}$ Tadros, 2005: p. 1011. Cf. "[T] he development of these more formal [criminal and civil] processes has several important ramifications in promoting public education and helping to redefine violence as a public issue. First, because of the availability of these legal remedies, there are more proceedings in court, and the participants, judiciary, court personnel, and public are educated about the problem of domestic violence. Public participation in these disputes may well have contributed to changing attitudes concerning the acceptability of violence against women. The media frequently focuses on court cases, so there are many articles in newspapers and programs on television about these cases. Analysis of the 
actual implementation of these legal remedies, and the failure of the courts to enforce these provisions, has been widely publicized in the many state gender bias reports and has further expanded an educational process within the states." Schneider, E. (1991). The Violence of Privacy. Connecticut Law Review, 23: 973-98: p. 989.

${ }^{56}$ See, e.g., "Whatever one thinks of the choice to criminalize as a means of making the private public, or expressing society's interest in stemming intimate partner violence, the message sent by repealing such statutes at this point would be problematic." Goodmark, L. (2017). Should Domestic Violence Be Decriminalized? Harvard Fournal of Law and Gender 53 (2017): p. 102.

${ }^{57}$ Coker, D. (2000). Shifting Power for Battered Women: Law, Material Resources, and Poor Women of Color. 33 U.C. Davis Law Review 1009, 1046-47; Richie, B. E. (2012). Arrested fustice Black Women, Violence, and America's Prison Nation. NYU Press: pp. 99-125.

${ }^{58}$ E.g. "A substantial majority of respondents reported that survivors frequently told them they were afraid that if they reported domestic or sexual violence to law enforcement, the state would remove their children." Coker, D. et al., (2015). Responses From The Field: Sexual Assault, Domestic Violence, And Policing. American Civil Liberties Union: p. 25.

${ }^{59}$ E.g. "Loddon Campaspe Community Legal Centre told the Commission that the results of their research project showed that none of the women surveyed felt that their 'justice needs' for offender accountability or restoration were met by the justice system response. Some of the women who participated in the research project identified restorative processes, such as opportunities to be heard in a more empowering and less adversarial forum, as having the potential to address their unmet needs." Victoria. Royal Commission into Family Violence. (2016). Report and recommendations / Royal Commission into Family Violence. Melbourne, Vic: p. 137.

${ }^{60}$ E.g. " $[\mathrm{I}]$ ntroducing restorative justice options must not provide a reason to avoid addressing the existing shortcomings of the justice system. Rather, restorative justice options should serve to supplement the outcomes available from the justice system." Royal Commission into Family Violence, 2016: p. 144.

${ }^{61}$ Cf. Howard Zehr, one of the most well-known RJ advocates, suggests that "domestic violence is probably the most problematic area of application, and here great caution is advised" Zehr, 2003: p. 11, 39. Again, "Feminist analysts face dilemmas in addressing the appropriateness of RJ for partner, sexual and family violence. Many desire a less stigmatizing and less punitive response to crime in general, but we are not sure that RJ, as currently practised, is capable of responding effectively to these offences." Daly and Stubbs, 2006: p. 17.

${ }^{62}$ Liebmann, M., \& Wootton, L. (2010). Restorative justice and domestic violence-abuse: A report commissioned by $\mathcal{F M P}$. Cardiff, Wales- Home Office Crime Reduction Unit.

${ }^{63}$ See, e.g., Kingi, V., Paulin, J., \& Porima, L. (2008). Delivery of restorative justice in family violence cases by providers funded by the Ministry of fustice. Wellington, New Zealand: Ministry of Justice. Retrieved from: $\quad$ www.justice.govt.nz/publications/global-publications/r/review-of-thedelivery-of-restorativejustice-in-family-violence-cases-by-providersfunded-by-the-ministry-of-justice-may- 2008.

${ }^{64}$ The following summation was made of the $\mathrm{NZ}$ study above, but is typical of every other evaluation: "It is not possible to draw clear conclusions from this evaluation because the research was conducted in different sites, somewhat different practices were used at each site, different kinds of abuse were included in the study, and only a small number of interviews with survivors and offenders were conducted." Ptacek, 2017: p. 172. Cf. "Although there is considerable debate on the appropriateness of RJ for partner, sexual or family violence, empirical evidence is sparse. There have been few studies of RJ for these offences . . . but insufficient attention has been paid to the great variation in the contexts and seriousness of these offences." Daly, K. and Stubbs, 2006: p. 18.

${ }^{65}$ Ptacek, 2017: p. 178.

${ }^{66}$ See Pennell, J. and Burford, G. (2000).Family group decision making: Protecting children and women", Child Welfare, 79(2), 131-158; and Pennell, J. and Burford, G. (2002). Feminist praxis: Making family group conferencing work. In H. Strang and J. Braithwaite (eds.), Restorative justice and family violence. 
${ }^{67}$ It should be noted here that the use of RJ for DV raises a number of complexities and dangers that are not generally present for sexual assault. As Koss acknowledges, "in established partnerships, sexual assault is typically accompanied by other forms of woman abuse including psychological and physical abuse, [whereas] more often acquaintance rapes are relatively isolated-albeit traumatic-events that are not followed by further acts of physical or sexual violence by the same perpetrator against the same victim. . . . Because of this difference, the concern that physical safety of the survivor may be compromised by the conference itself is more relevant in cases of ongoing battering than in cases of acquaintance sexual assault.” Koss, 2014: p. 709.

${ }^{68}$ RESTORE stands for 'Responsibility and Equity for Sexual Transgressions Offering a Restorative Experience'.

${ }^{69}$ Koss, 2014: p. 697. See also Koss, M. P. and Achilles, M. (2008). Restorative justice approaches to sexual assault. VAWnet. Retrieved from: http://new.vawnet.org/ Assoc_Files_VAWnet/AR_RestorativeJustice.pdf; and Koss, M.P., Bachar, K., Hopkins, C.Q. and Carlson, C. (2004). Expanding a community's justice response to sex crimes through advocacy, prosecutorial, and public health collaboration: Introducing the RESTORE program. Fournal of Interpersonal Violence, 19(12), 1435-1463.

70 Almeida, R. V. and Dolan-Delvecchio, K. E. N. (1999). Addressing Culture in Batterers Intervention: The Asian Indian Community as an Illustrative Example. Violence Against Women, 5(6), 654-683.

${ }^{71} \mathrm{Cf}$. "I believe that the current practice of using western RJ and Aboriginal justice in cases of intimate violence, without clear evidence that it is safe and effective, is gambling with the lives and safety of Canadian women. In Canada we are well positioned to re-analyse data that have already been gathered from several major initiatives that have been in place for some time. Thus, research can proceed without further jeopardizing the safety of victims. Research should examine factors such as offender's manipulation of the process, emphasis on reconciliation, the resources available to violent men and to victims, and the presence or absence of feminist voices in planning, executing and evaluating these initiatives." Cameron, A. (2006). Stopping the violence-Canadian feminist debates on restorative justice and intimate violence. Theoretical Criminology, 10(1), 49-66: pp. 59-60.

72 Daly and Stubbs, 2006: p. 18.

${ }^{73}$ Cf. "Extensive engagement and preparation with families, supports for families, the provision of preventative domestic violence services and, ultimately, beginning to unpick the structural and power inequalities underlying domestic violence, are all necessary ingredients to making restorative approaches work well." Sen, R., Morrisa, K., Burford, G., Featherstone, B. and Webb, C. (2018). 'When you're sitting in the room with two people one of whom . . . has bashed the hell out of the other': Possibilities and challenges in the use of FGCs and restorative approaches following domestic violence. Children and Youth Services Review, 88, 441-449: p.448.

74 “ $[\mathrm{T}]$ he group linked the struggle for gender equality with the struggle for racial and economic justice. Other programs for heterosexual men of colour who batter similarly focus on relating the experiences of racial/ethnic subordination to the men's own use of power to subordinate their female partners . . . All stress that the man's own experiences of oppression do not excuse or justify his own oppressive behaviour. All seek to enable men to redefine their masculinity in ways that do not depend on oppressing women." Coker, 2002: p. 146.

75 "[The process should offer] an alternative to the separation focused interventions of the dominant forms of justice intervention. It [should help] women build a community that supports women's autonomy without forcing women to choose between their ethnic/racial communities and safety." Coker, 2002: p. 148.

${ }^{76}$ Coker, 2002: p. 130.

${ }^{77} \mathrm{Cf}$. "[W]omen in ongoing violent relationships are not as interested in restoring relationships as they are in utterly transforming them." Cheon and Regehr, 2006: p. 385.

78 This term is also advocated in Morris, R. (2000). Stories of Transformative Fustice. Canadian Scholars' Press, Inc.: Ontario. 